\title{
ANÁLISE DO PERFIL LONGITUDINAL DO ALTO/MÉDIO RIO GRANDE - MG: GÊNESE DE RUPTURAS DE DECLIVE E DISTRIBUIÇÃO DE REGISTROS SEDIMENTARES
}

\author{
Éric Andrade Rezende ${ }^{(a)}$, Paulo de Tarso Amorim Castro ${ }^{(b)}$ \\ (a) Departamento de Geologia/Universidade Federal de Ouro Preto, ear.88@hotmail.com \\ (b) Departamento de Geologia/Universidade Federal de Ouro Preto, ptacastro@gmail.com
}

EIXO: SISTEMAS GEOMORFOLÓGICOS: ESTRUTURAS, DINÂMICAS E PROCESSOS

\begin{abstract}
Resumo
O presente trabalho tem como objetivo identificar as principais zonas de ruptura no perfil longitudinal do alto/médio Rio Grande, sul de Minas Gerais. Pretende-se analisar os possíveis condicionantes da gênese dessas feições, seus reflexos na distribuição de antigos registros sedimentares aluviais e na diferenciação entre as formas de relevo. Foram identificadas quatro zonas de ruptura que possuem origens distintas e marcante influência sobre as características geomorfológicas das áreas drenadas a montante e a jusante. A origem das quatro rupturas está relacionada aos seguintes fatores: (1) controle litológico; (2) superimposição sobre quartzitos; (3) controle litológico e tectônico, (4) retração erosiva. Variações na intensidade do entalhamento são condicionadas principalmente pela proximidade de soleiras geomórficas quartzíticas. A quarta zona de ruptura é a que mais claramente separa domínios geomorfológicos com diferentes níveis de rejuvenescimento. A montante ocorre o Graben de Ijaci, que concentra a maioria dos depósitos fluviais encontrados ao longo do vale.
\end{abstract}

Palavras chave: nível de base, incisão fluvial, terraços fluviais, morfotectônica, litoestrutura

\section{Introdução}

A gênese de rupturas de declive no perfil longitudinal de cursos fluviais pode estar associada basicamente a três condicionantes distintos: contraste litológico (BULL, 2007), movimentos tectônicos (LARUE, 2008; BURBANK \& ANDERSON, 2011) e retração erosiva a partir de um rebaixamento do nível de base (SCHUMM 2005; CHARLTON, 2008; OLIVETTI et al. 2016). No primeiro caso a presença de uma rocha mais resistente à erosão fluvial a montante de uma rocha mais friável pode criar um desnível entre elas. Ou seja, a rocha mais resistente atua como uma soleira geomórfica. O segundo caso corresponde a um degrau gerado por uma falha com movimentação vertical relativamente recente. Já o terceiro caso pode resultar do rebaixamento do nível de base provocado por um dos processos anteriormente mencionados, e corresponde a uma vaga erosiva que se propaga para montante aproveitando-se de um gradiente localmente acentuado. Uma possibilidade alternativa é a gênese de rupturas a partir da superimposição de um canal sobre uma estrutura rochosa resistente que anteriormente encontrava-se recoberta por materiais mais suscetíveis à erosão. Uma combinação entre os diferentes tipos de gênese também pode ocorrer. 
Cada um desses tipos de ruptura de declive resulta em dinâmicas fluviais diferenciadas entre os segmentos a montante e a jusante e, consequentemente em padrões de relevo também distintos. Nas rupturas controladas litologicamente, a rede de drenagem a montante tende a ser mais estável, com incisão pouco pronunciada ou agradação (BULL, 2007). Já no caso de controle tectônico, o bloco soerguido, a montante, tende a ter sua rede de drenagem rejuvenescida por incisão, enquanto no bloco a jusante a sedimentação pode se sobrepor (SCHUMM, 2005). Na retração de rupturas de declive, a passagem da vaga erosiva tende a deixar como registro um relevo dissecado, enquanto os compartimentos a montante permanecem mais estabilizados (SCHUMM, 2005; OLIVETTI et al., 2016). Neste contexto, o presente trabalho tem como objetivo identificar as principais zonas de ruptura no perfil longitudinal do Rio Grande, a montante da usina hidrelétrica de Furnas, no sul de Minas Gerais (Figura 1). Além disso, pretende-se analisar os possíveis condicionantes da gênese dessas feições, seus reflexos na distribuição de antigos registros sedimentares aluviais e na diferenciação entre as formas de relevo.

A alta/média bacia do Rio Grande está localizada no contato entre a borda sul do Cráton do São Francisco e a zona de interferência entre os orógenos Brasília (NNW-SSE) e Ribeira (NE-SW), ambos desenvolvidos durante a Orogenia Brasiliano-Pan Africana, ocorrida no Neoproterozoico (HEILBRON et al., 2004; TROUW et al., 2013). Na região, o Rio Grande cruza por rochas cristalinas do embasamento paleoproterozoico-arqueano, metassedimentos proterozoicos dos grupos São João del Rei, Carandaí, Andrelândia, Araxá, Canastra e Bambuí, além de granitoides neoproterozoicos (CAMPOS NETO et al., 2004; HEILBRON et al., 2004; ALKMIM \& MARTINS-NETO, 2012). De acordo com Saadi et al. (1998), a bacia do Rio Grande tem sua evolução geomorfológica ligada a variações do nível de base ocorridas desde o soerguimento pós-cretácico da Serra da Mantiqueira, que corresponde ao seu limite sul/sudeste.

\section{Procedimentos metodológicos}

O perfil longitudinal foi gerado no software ArcGis 10.3 tendo como base o modelo digital de elevação SRTM (Shuttle Radar Topography Mission) com resolução espacial de 30 m (USGS). Em seguida o perfil foi manipulado em planilha eletrônica, onde foi possível inserir a posição de limites litológicos, estruturas geológicas e níveis deposicionais mapeados em campo. Foi utilizado como base o Mapa Geológico de Minas Gerais (PINTO \& SILVA, 2014), apoiado por mapas geológicos na escala de 1:100.00. Posteriormente foram identificados os diferentes segmentos do rio que encontram-se limitados pelas rupturas de declive. Também foram analisados os possíveis fatores associados a gênese das principais rupturas de declive e o papel destas como níveis de base que controlam a intensidade da incisão 


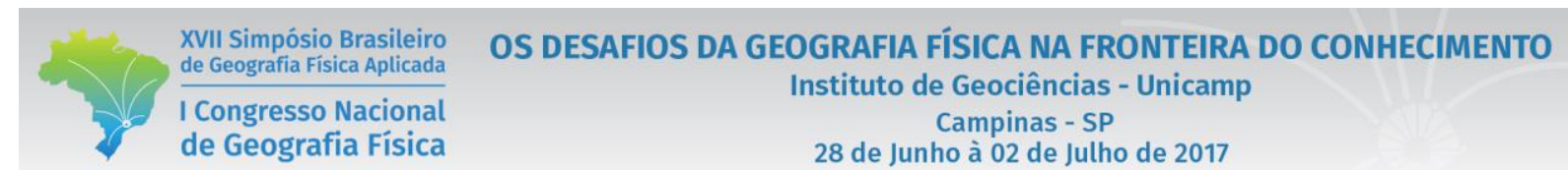

fluvial. Para isso foi utilizado como apoio o trabalho de Rezende \& Castro (2016), que representou cartograficamente a distribuição espacial do entalhamento fluvial na bacia do Rio Grande.

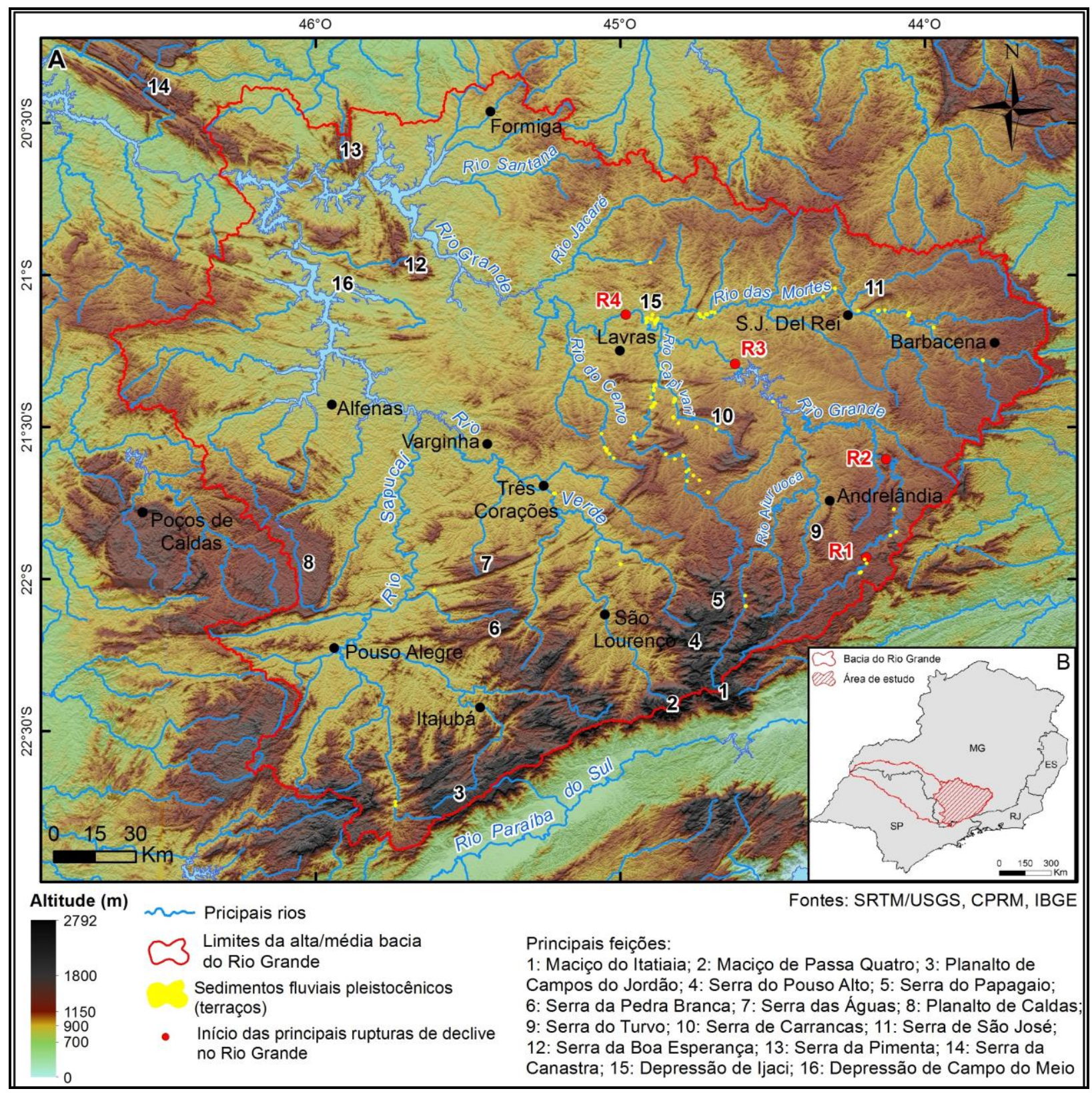

Figura 1 - Localização da área de estudo. A) Modelo digital de elevação com limites da bacia do Rio Grande a montante da barragem de Furnas e localização das principais zonas de ruptura no Rio Grande (R1, R2, R3, R4); B) Localização da bacia do Rio Grande no sudeste brasileiro.

Com o intuito de identificar a localização de possíveis rupturas de declive atualmente encobertas pela represa de Furnas foram consultados mapas antigos elaborados pela Secretaria de viação e obras públicas de Minas Gerais (1939). Nestes mapas (folhas Guapé e Alpinópolis) consta a localização das 


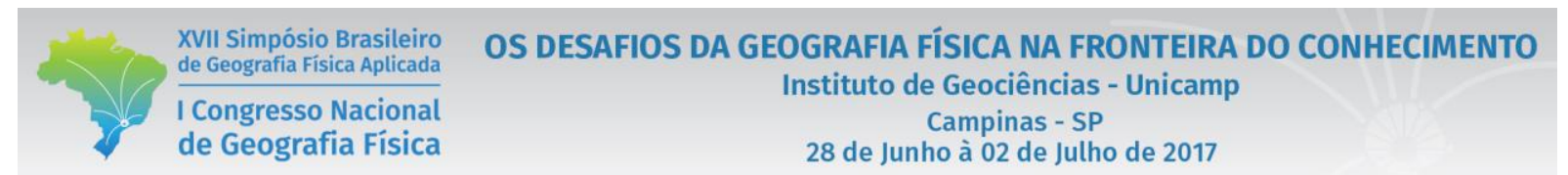

principais cachoeiras e/ou corredeiras do Rio Grande na região de Guapé. No entanto, não há mapas topográficos anteriores ao represamento que permitam uma reconstituição fidedigna do perfil longitudinal na área inundada.

\section{Resultados e discussões}

O percurso do Rio Grande até a barragem de Furnas totaliza $722 \mathrm{~km}$ de extensão e um desnível de aproximadamente $1500 \mathrm{~m}$ desde a sua nascente na Serra da Mantiqueira. Há predomínio de um baixo gradiente na maior parte do seu trajeto, conforme mostra a Figura 2. Seu perfil longitudinal aponta a presença de quatro zonas de ruptura principais e pode ser dividido em seis segmentos (Tabela 1). O ponto inicial de cada ruptura está representado na Figura 1. Nenhuma delas está associada à desembocadura de grandes tributários que possam causar um significativo aumento local da vazão.

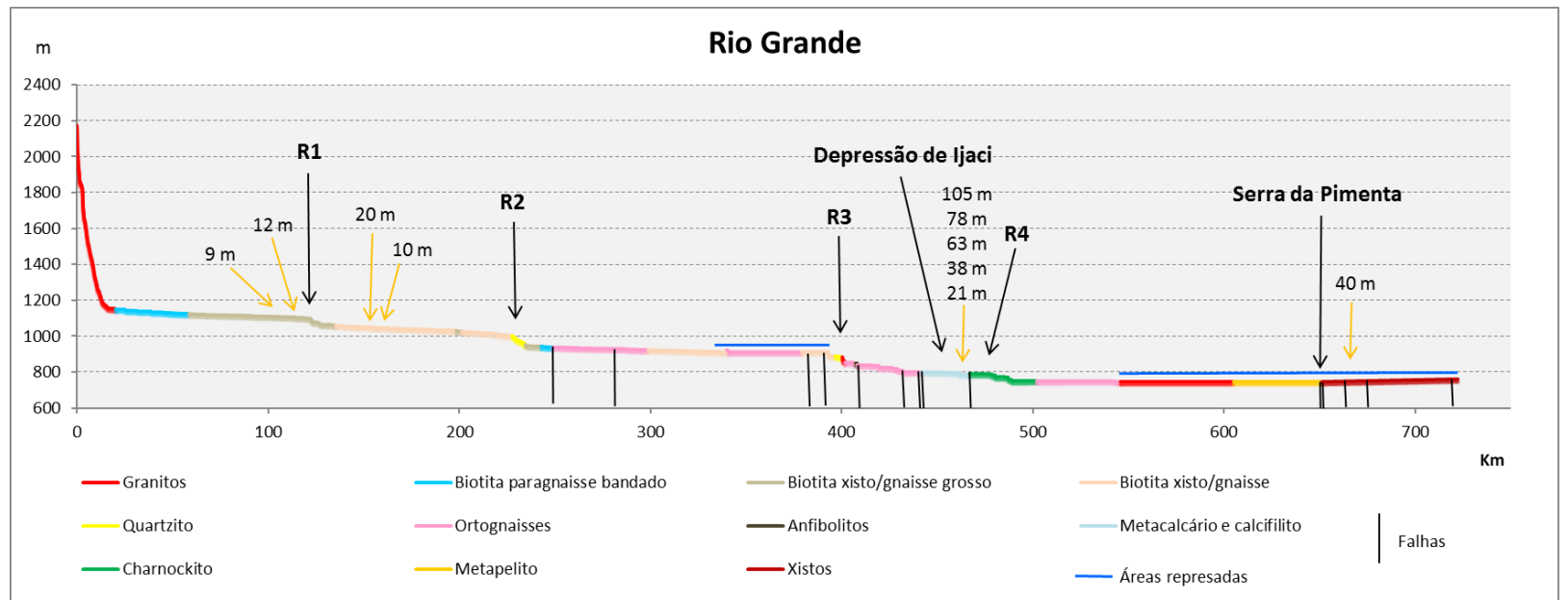

Figura 2 - Perfil longitudinal do Rio Grande com localização das principais rupturas (R1, R2, R3, R4). Setas laranjas indicam a localização de antigos depósitos aluviais e suas respectivas alturas aproximadas em relação ao canal. Observações: Falhas traçadas verticalmente para representação simplificada. Áreas represadas (sob traço azul) não refletem a altitude real do leito. Faixas muito estreitas de determinadas litologias não foram representadas por questão de escala. Fonte das informações geológicas: Mapa Geológico do Estado de Minas Gerais (PINTO \& SILVA, 2014), com apoio de mapas na escala de 1:100.000.

Nos 14 primeiros quilômetros há um desnível de 995 m, que se traduz em um gradiente muito elevado (71 $\mathrm{m} / \mathrm{km}$ ). Nesse trecho inicial o rio encontra-se adaptado a uma falha de direção ENE e assume a forma de corredeiras sobre leito rochoso granítico. As cristas que limitam o vale chegam a superar $2000 \mathrm{~m}$ de altitude em diversos pontos. Portanto, é um trecho com predomínio absoluto dos processos erosivos sobre os deposicionais, o que resulta na total ausência de antigos registros sedimentares aluviais. Os únicos depósitos existentes são os oriundos dos movimentos de massa que afetam as vertentes escarpadas adjacentes. A ausência de marcadores impede uma avaliação precisa do entalhamento processado pelo Rio 
Grande ao longo do Quaternário. No entanto, o vale em V, as vertentes escarpadas e o acentuado gradiente sugerem uma intensa incisão fluvial. Esse cenário é compatível com os resultados obtidos por Rezende \& Castro (2016), onde as cabeceiras do Rio Grande aparecem como uma das áreas potencialmente mais soerguidas da bacia. Rezende et al. (2013) estimaram a taxa média de denudação dessa porção da alta bacia do Rio Grande através da mensuração do isótopo cosmogênico ${ }^{10} \mathrm{Be}$ em sedimentos fluviais. A taxa calculada foi de $14,53 \pm 0,5 \mathrm{~mm} / \mathrm{ka}$ e posteriormente revisada para 17,2 $\pm 0,7 \mathrm{~mm} / \mathrm{ka}$, em um período de integração correspondente a 32,1 mil anos (Salgado et al. 2016). Trata-se de uma taxa que reflete a média dos processos denudacionais em toda a área a montante do ponto de amostragem. As características geomorfológicas da área sugerem que a taxa de incisão quaternária desse trecho do Rio Grande deva ser consideravelmente superior à taxa média de denudação mensurada.

Após os 14 quilômetros iniciais o Rio Grande passa a apresentar um gradiente muito baixo associado a um padrão meandrante e a uma ampla planície de dimensões anômalas. Essa brusca mudança em relação ao segmento anterior ocorre próxima ao contato entre granitos, a montante, e paragnaisses, a jusante (Figura 2). O segmento de baixo gradiente $(0,74 \mathrm{~m} / \mathrm{km})$ persiste até a primeira zona de ruptura no perfil longitudinal, localizada a $122 \mathrm{~km}$ da nascente, logo a jusante da cidade de Bom Jardim de Minas. A atual colmatação do vale é resultado do grande aporte sedimentar oriundo das cabeceiras montanhosas somado à presença de uma soleira quartzítica que atua como um nível de base regional junto à primeira ruptura de declive. $O$ contraste entre vales entulhados e encostas declivosas ( $>25 \%)$ sugere uma mudança relativamente recente nos processos fluviais predominantes, onde a deposição se sobrepôs à incisão. Um controle tectônico local na forma de pequenos grabens pode ter acentuado essa tendência deposicional recente, como sugerem as frequentes facetas triangulares em parte das escarpas que limitam o vale. $\mathrm{O}$ paralelismo com as estruturas ENE do Rift Continental do Sudeste Brasileiro (RICCOMINI et al., 2004) e a presença de estruturas cenozoicas de mesma direção ali mapeadas pelo NEOTEC (MORALES et al., 2014) reforçam essa hipótese. Apenas após os $100 \mathrm{~km}$ iniciais surgem os primeiros depósitos fluviais cascalhosos dispostos em terraços pouco acima da planície e com desnível crescente em relação à calha (10 a $18 \mathrm{~m})$.

A primeira zona de ruptura possui um desnível de aproximadamente $21 \mathrm{~m}$ ao longo de $920 \mathrm{~m}$ de corredeiras (Figura 3A). Está sobre a formação Arantina, composta predominantemente por gnaisses e xistos. Na margem direita há um contato mapeado com a Formação São Tomé das Letras, composta por quartzitos. Localmente, os quartzitos que afloram nos trechos de corredeiras não deixam dúvida sobre o controle litológico na formação da ruptura. Sua maior resistência em relação aos gnaisses/xistos, situados a jusante, é responsável pela formação do degrau no perfil longitudinal. A leste desse trecho do rio 
(margem direita) os quartzitos sustentam serras com altitudes superiores a $1500 \mathrm{~m}$ (serras do Governo e

São Pedro). Não há falhas mapeadas nas proximidades da ruptura.

Tabela I - Extensão, gradiente, litologia e amplitude do vale nos segmentos identificados (inclui zonas de ruptura)

\begin{tabular}{|c|c|c|c|}
\hline Segmento & $\begin{array}{l}\text { Gradiente total } \\
\text { do segmento }\end{array}$ & Litologia principal & $\begin{array}{c}\text { Registros sedimentares/ amplitude de } \\
\text { relevo }\end{array}$ \\
\hline $1(0$ a $14 \mathrm{~km})$ & $\begin{array}{l}71 \mathrm{~m} / \mathrm{km}(2173 \\
-1178 \mathrm{~m})\end{array}$ & Granito & $\begin{array}{l}\text { Leito rochoso. Ausência de planície e de } \\
\text { terraços fluviais. } \\
\text { Amplitude de relevo do vale acima de } 200 \mathrm{~m} \text {. }\end{array}$ \\
\hline $2(14$ a $122 \mathrm{~km})$ & $\begin{array}{l}0,74 \mathrm{~m} / \mathrm{km} \\
(1178-1098 \mathrm{~m})\end{array}$ & Gnaisse & $\begin{array}{l}\text { Ampla planície aluvial na maior parte do } \\
\text { segmento. Um nível deposicional com } \\
\text { ocorrências esparsas entre } 10 \text { e } 18 \mathrm{~m} \text { acima da } \\
\text { calha atual. } \\
\text { Amplitude de relevo do vale entre } 100 \text { e } 200 \\
\text { m, em média. }\end{array}$ \\
\hline $\begin{array}{l}3(122 \text { a } 228 \\
\mathrm{km})\end{array}$ & $\begin{array}{l}0,94 \mathrm{~m} / \mathrm{km} \\
(1098-998 \mathrm{~m})\end{array}$ & Xisto/gnaisse e quartzito & $\begin{array}{l}\text { Planície de dimensão restrita ou ausente. Dois } \\
\text { níveis deposicionais com ocorrência restrita a } \\
20 \mathrm{~m} \text { e } 10 \mathrm{~m} \text { acima do canal atual. } \\
\text { Amplitude de relevo do vale entre } 50 \text { e } 100 \mathrm{~m} \text {, } \\
\text { em média. }\end{array}$ \\
\hline $\begin{array}{l}4(228 \text { a } 400 \\
\text { km) }\end{array}$ & $\begin{array}{l}0,74 \mathrm{~m} / \mathrm{km}(998 \\
-870 \mathrm{~m})\end{array}$ & $\begin{array}{l}\text { Quartzito, xisto/gnaisse, } \\
\text { gnaisse e ortognaisses }\end{array}$ & $\begin{array}{l}\text { Planície de dimensão restrita, ausente ou } \\
\text { represada. } \\
\text { Ausência de terraços fluviais (apenas um } \\
\text { depósito no baixo curso de um afluente a } \sim 23 \\
\text { m acima do canal). } \\
\text { Amplitude de relevo do vale entre } 50 \text { e } 100 \mathrm{~m} \text {, } \\
\text { em média. }\end{array}$ \\
\hline $\begin{array}{c}5(400 \text { a } 479 \\
\mathrm{km})\end{array}$ & $\begin{array}{l}1,08 \mathrm{~m} / \mathrm{km}(870 \\
-785 \mathrm{~m})\end{array}$ & $\begin{array}{l}\text { Quartzito, granito, } \\
\text { ortognaisse, } \\
\text { metacalcário/calcifilito, } \\
\text { charnockito }\end{array}$ & $\begin{array}{l}\text { Planície de dimensão restrita ou ausente e } \\
\text { terraços ausentes a montante e a jusante da } \\
\text { Depressão de Ijaci. } \\
\text { Ampla planície e cinco níveis deposicionais } \\
\text { na Depressão de Ijaci. } \\
\text { Amplitude de relevo do vale entre } 50 \text { e } 100 \mathrm{~m} \text {, } \\
\text { em média. }\end{array}$ \\
\hline $\begin{array}{c}6(479 \text { a } 722 \\
\mathrm{km})\end{array}$ & $\begin{array}{l}0,47 \mathrm{~m} / \mathrm{km}(785 \\
-670 \mathrm{~m})\end{array}$ & $\begin{array}{l}\text { Charnockito, ortognaisse, } \\
\text { granito, metapelito, xisto, } \\
\text { quartzito }\end{array}$ & $\begin{array}{l}\text { Planície ausente, restrita ou represada. } \\
\text { Amplitude de relevo do vale entre } 60 \text { e } 120 \text { m, } \\
\text { em média. }\end{array}$ \\
\hline
\end{tabular}

Logo após, o Rio Grande adentra um novo segmento de baixo gradiente que perdura até a segunda zona de ruptura, localizada a $228 \mathrm{~km}$ da nascente (Figura 2), a jusante da cidade de Santana do Garambéu. A área drenada por esse seguimento apresenta um relevo mais suave que a área a montante, o que indica uma maior estabilidade do nível de base durante o Neocenozoico (REZENDE \& CASTRO, 2016). Contudo, registros sedimentares também são raros, a exemplo do que ocorre no segmento anterior. Apenas dois depósitos aluviais foram encontrados, a $20 \mathrm{~m}$ e $10 \mathrm{~m}$ acima da calha atual. A planície passa a ter dimensões mais modestas e em alguns trechos deixa de ocorrer. 


$\begin{gathered}\text { XVII Simpósio Brasileiro } \\ \text { de Geografia Fisica Aplicada }\end{gathered}$
$\begin{aligned} & \text { ICongresso Nacional } \\ & \text { de Geografia Física }\end{aligned}$

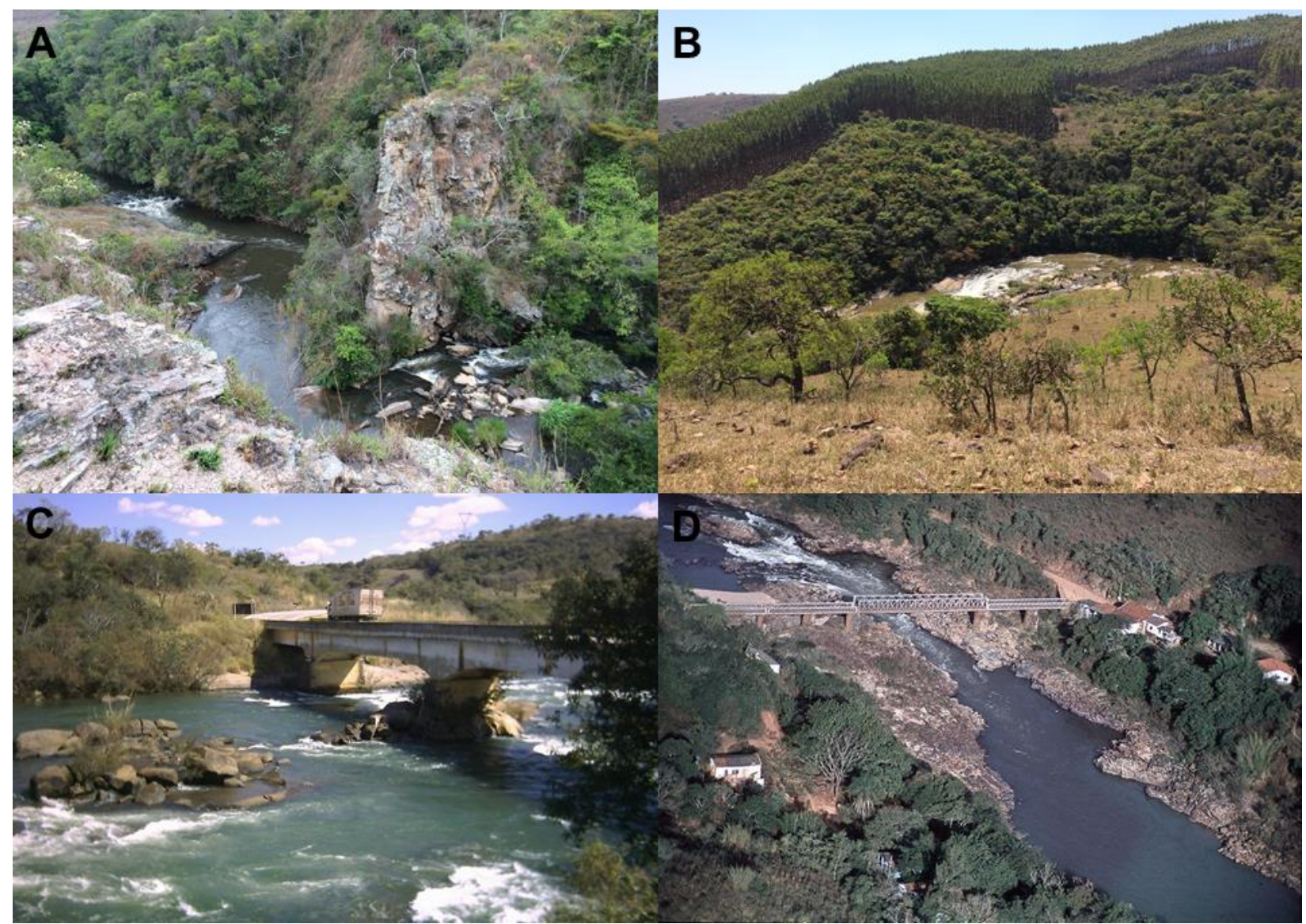

Figura 3 - Fotos das quatro principais zonas de ruptura no alto/médio Rio Grande. A) Primeira ruptura - Bom Jardim de Minas; B) Parte da segunda ruptura - Santana do Garambéu; c) Parte da terceira ruptura - BR-265, Nazareno/Itutinga; D) Parte da quarta ruptura - antiga ponte do Funil hoje submersa - Lavras/Perdões. Autoria das fotos: A e B: próprias; C: Paulo Nogueira; D: Ana Nogueira.

A segunda zona de ruptura possui um desnível de $50 \mathrm{~m}$ e estende-se por 7,8 $\mathrm{km}$ de corredeiras descontínuas $(6,4 \mathrm{~m} / \mathrm{km})$ entre a Serra dos Cataguases (Figura 3B). Não está relacionada diretamente a nenhum contato litológico e também não há falhas mapeadas em sua extensão. Está em sua maior parte sobre quartzitos, o que sugere que as corredeiras são uma resposta do rio a maior necessidade de energia para erodir tais rochas. O estabelecimento do canal transversalmente a serra quartzítica constitui uma anomalia cuja origem deve estar relacionada à superimposição do Rio Grande e de seus afluentes sobre as estruturas dobradas e falhadas ao sul do Cráton do São Francisco. O declive gradual da zona de ruptura indica um processo já bastante avançado de desgaste erosivo. A falha mapeada mais próxima está cerca de $19 \mathrm{~km}$ a jusante, no contato entre o Sistema de Nappes Andrelândia e o embasamento Paleoproterozoico/Arqueano (TROUW et al., 2013). Um recuo erosivo a partir de uma possível reativação desta falha também pode ter contribuído para a gênese das corredeiras. O papel dos quartzitos como 
soleira é relativamente limitado, já que não há acumulação aluvial significativa a montante da garganta/ruptura.

O quarto segmento também é caracterizados por um baixo gradiente que persiste até a usina hidrelétrica de Itutinga, próximo a cidade homônima e a $400 \mathrm{~km}$ da nascente. A construção das usinas hidrelétricas de Itutinga e, principalmente, de Camargos (36 $\mathrm{m}$ de altura) na década de 50 inundou boa parte desse segmento do Rio Grande. Esse fato prejudica tanto análise do perfil longitudinal gerado a partir de MDE, como a identificação de possíveis depósitos sedimentares. Contudo, o predomínio de colinas de baixa amplitude indica que esse é o segmento do Rio Grande onde a incisão fluvial foi menos intensa (REZENDE \& CASTRO, 2016).

A soleira formada pelo quartzito Itutinga deve ser a principal responsável pela relativa estabilidade do nível de base no trecho em questão. Curiosamente não foram encontrados depósitos fluviais diretamente associados ao Rio Grande, o que dificulta a avaliação da incisão no trecho. O único depósito encontrado está no baixo curso do Ribeirão do Clemente, um afluente da margem esquerda, a cerca de $23 \mathrm{~m}$ acima do canal (atualmente represado). Contatos entre ortognaisses, granitoides e xistos/gnaisses não condicionam nenhuma ruptura no perfil longitudinal.

Não é possível localizar o início da terceira zona de ruptura (Figura 3C) com precisão devido aos represamentos. No entanto, seu topo aparenta estar associado ao contato entre quartzitos da Formação Itutinga e granitos/granodioritos, no local da antiga "Cachoeira de Itutinga" e logo a jusante de uma pequena garganta onde o rio cruza a Serra do Ouro Grosso. Essa zona declivosa sobre leito rochoso ocorre na forma de corredeiras descontínuas que se estendem por $30 \mathrm{~km}$ e cortam ortognaisses, anfibolitos, dioritos e gabros, assim como a zona de cisalhamento de Nazareno (ENE). O desnível total é de aproximadamente $60 \mathrm{~m}(2 \mathrm{~m} / \mathrm{km})$. A continuidade das corredeiras por vários quilômetros indica também um processo de rejuvenescimento ativo provocado por um rebaixamento do nível de base no "Graben de Ijaci”, que será detalhado à frente. O desequilíbrio do trecho pode ainda ter sido acentuado por movimentações recentes da zona de cisalhamento de Nazareno, como já sugerido por Rezende \& Castro (2016). Portanto, a morfologia atual da extensa zona de ruptura é um resultado da conjunção de controles litológicos, tectônicos e erosivos.

O quinto segmento possui uma extensão de $48 \mathrm{~km}$ e é caracterizado por um baixo gradiente no perfil longitudinal após as corredeiras iniciais. Há um notável decréscimo nas altitudes em relação à área drenada pelo segmento anterior (Figura 1), o que reforça o papel da terceira ruptura como um importante nível de base. A maior parte desse segmento está inserida em uma pequena depressão situada na região de Ijaci, junto à desembocadura de dois importantes afluentes: os rios Capivari e das Mortes. Essa depressão possui altitudes entre 800 e $840 \mathrm{~m}$ e é limitada por elevações entre 900 e $1020 \mathrm{~m}$. A área deprimida foi 
chamada de "Graben de Ijaci" por Quéméneur et al. (2003) e coincide aproximadamente com uma ocorrência de metacalcários do Grupo Carandaí, limitada por falhas de direção NNE e ESE. As duas estruturas NNE, perpendiculares ao rio e paralelas à Serra de Bom Sucesso, foram mapeadas como falhas cenozoicas por Saadi (1991), que também interpretou a área como um graben em seu "esboço morfotectônico da bacia do alto Rio Grande". Dehler \& Machado (1998) sugerem um importante componente de movimentação normal nas zonas de cisalhamento que delimitam a depressão a sul e leste. Os extensos depósitos aluviais ali presentes, hoje parcialmente encobertos pelo reservatório do Funil, não encontram paralelo em nenhum outro trecho do alto/médio Rio Grande. Há pelo menos cinco níveis deposicionais com topos a cerca de 105, 78, 63, 38 e 21 metros acima do canal. Nas proximidades da confluência com o Rio das Mortes há exposições com cerca de $30 \mathrm{~m}$ de espessura. A ampla planície encontra-se atualmente submersa.

As características citadas indicam que a depressão de Ijaci esteve periodicamente sob subsidência durante o Quaternário. Essa subsidência relativa ao entorno foi intercalada com episódios de incisão, o que explica o escalonamento dos níveis deposicionais. Sismos registrados pelo Observatório Sismológico da UNB nos últimos anos constituem mais uma evidência da atividade neotectônica na região. O rebaixamento do nível de base associado a esse graben certamente foi um dos responsáveis pela gênese da terceira zona de ruptura, citada anteriormente, já que as corredeiras estão posicionadas poucos quilômetros a montante da área subsidente. Portanto, trata-se de uma região chave para o entendimento da evolução geomorfológica da bacia do Rio Grande.

A $479 \mathrm{~km}$ da nascente e a poucos quilômetros do graben de Ijaci tem início uma nova zona de ruptura inteiramente situada sobre charnockitos (Figura 2 e 3D). Essa zona de ruptura possui extensão de 11,5 km e desnível de $35 \mathrm{~m}$, o que resulta em um gradiente de $3,1 \mathrm{~m} / \mathrm{km}$. Atualmente está sob as águas da Represa do Funil, concluída em 2002. Não há falhas mapeadas ou contatos litológicos associados diretamente a ela. Deste modo, sua atual posição deve ser resultante da retração de um knickpoint gerado a jusante. Pouco após o fim das corredeiras o rio se estabelece no contato entre charnockitos e ortognaisses, e em seguida passa a correr apenas sobre ortognaisses dos complexos Campo Belo e Campo Gerais. Portanto, é provável que o knickpoint original tenha sido gerada no contato entre o Charnockito Ribeirão Vermelho, mais resistente, e os ortognaisses, mais frágeis. Zonas de cisalhamento e diques de direção WNW-ESSE, abundantes a oeste de Lavras, também podem ter contribuído para uma maior incisão local do Rio Grande e consequentemente para o rebaixamento do nível de base necessário para formação da anomalia no perfil longitudinal. É interessante notar que a jusante dessa ruptura passa a predominar um entalhamento fluvial superior a $80 \mathrm{~m}$ na área drenada pelo Rio Grande (REZENDE \& CASTRO, 2016), o que sugere um maior rejuvenescimento do relevo em relação à área drenada pelos segmentos 4 e 5 . 
Após a quarta zona de ruptura tem início um longo segmento de baixo gradiente, cujo final não é possível identificar com precisão devido ao represamento causado pela barragem de Furnas. Os contatos entre charnockitos, ortognaisses, granitos e metapelitos não aparentam condicionar rupturas significativas no perfil longitudinal. É provável que esse segmento pouco declivoso persista pelo menos até a garganta onde o Rio Grande cruza a Serra da Pimenta, constituída por quartzitos e localizada a sudoeste de Formiga (Figura 1). A jusante dessa drenagem transversal os diversos afloramentos quartzíticos intercalados a metapelitos condicionam vales mais profundos, por vezes bordejados por escarpas. Mapas produzidos pela Secretaria de viação e obras públicas de Minas Gerais (1939) indicam a presença de pelo menos sete cachoeiras/corredeiras entre a Serra da Pimenta e a Serra do Cigano, onde foi construída a barragem de Furnas. Portanto, o perfil longitudinal construído através dos dados SRTM não reflete o gradiente real devido ao represamento. A sequência de corredeiras entre as serras citadas constituía originalmente uma extensa zona declivosa anômala também associada a superimposição do Rio Grande sobre as estruturas da Faixa Brasília. Nesse último segmento foi encontrado um único depósito, localizado em Guapé, alguns quilômetros a jusante da garganta na Serra da Pimenta e a uma altura estimada de $40 \mathrm{~m}$ em relação ao canal.

Após a barragem, situada logo a jusante de uma falha normal, o Rio Grande adentra uma depressão com altitudes predominantes entre 650 e $750 \mathrm{~m}$. Localizada aos pés da Serra da Canastra, essa depressão pode ser interpretada como um compartimento análogo à Depressão Periférica Paulista, com a diferença que nesta última afloram rochas sedimentares paleozoicas, enquanto na primeira afloram rochas précambrianas. Essas depressões foram escavadas na borda oriental da bacia sedimentar do Paraná a partir do Paleoceno/Eoceno (PINHEIRO \& QUEIROZ NETO, 2014), o que constitui um marco temporal do início da superimposição das principais drenagens regionais sobre as estruturas da Faixa Brasília. As numerosas gargantas que cortam cristas com altitudes superiores a $1200 \mathrm{~m}$ são registros desse processo de superimposição que foi fundamental para a elaboração do relevo da bacia do Rio Grande durante o Cenozoico.

\section{Considerações Finais}

Entre a sua nascente e a barragem de Furnas o Rio Grande apresenta quatro zonas de ruptura de declive principais em seu perfil longitudinal. Cada uma dessas feições possui uma origem distinta, porém, guardam em comum a marcante influência sobre as características geomorfológicas das áreas drenadas a montante e a jusante. A primeira ruptura atua como uma soleira geomórfica e tem sua gênese relacionada a um controle litológico. A segunda é uma drenagem transversal, resultante da superimposição sobre quartzitos. A terceira é a mais extensa e de origem mais complexa, já que seu topo possui um controle 
litológico, enquanto a jusante a subsidência episódica do Graben de Ijaci e a provável reativação da zona de cisalhamento de Nazareno geraram um trecho em desequilíbrio marcado pela presença de diversas corredeiras. A quarta é resultante de um recuo erosivo a partir de um contato entre charnockitos e ortognaisses. A análise de mapas antigos confirmou ainda a existência de uma quinta sequência de corredeiras no final do trecho estudado e que atualmente encontra-se encoberta pela Represa de Furnas.

Antigos depósitos fluviais são raros ao longo do vale, o que demonstra o predomínio de condições desfavoráveis à sua de deposição e/ou preservação. A região do Graben de Ijaci concentra a maioria das ocorrências, localmente distribuídas em pelo menos cinco níveis deposicionais escalonados que indicam a alternância entre períodos de deposição e incisão. A existência de terraços fluviais a mais de $70 \mathrm{~m}$ acima do canal atual evidência um considerável entalhamento do vale durante o Quaternário com o consequente rejuvenescimento do relevo regional. Variações na intensidade do entalhamento são condicionadas principalmente pela proximidade de soleiras geomórficas constituídas por quartzitos. A quarta zona de ruptura é a que mais claramente separa domínios geomorfológicos com diferentes níveis de rejuvenescimento. A jusante, se configura uma depressão com relevo predominantemente mais dissecado, altitudes inferiores a $900 \mathrm{~m}$ e notável escassez de depósitos fluviais. A montante, a altitude dos níveis planálticos cresce progressivamente em direção às cabeceiras na Serra da Mantiqueira e os registros sedimentares são mais frequentes.

\section{Bibliografia}

ALKMIM, F. F.; MARTINS-NETO, M. A. Proterozoic first-order sedimentary sequences of the São Francisco craton, eastern Brazil. Marine and Petroleum Geology, v. 33, n. 1, p. 127-139, 2012.

BULL, W. B. Tectonic geomorphology of mountains: a new approach to paleoseismology. John Wiley \& Sons, 2008. $316 \mathrm{p}$.

BURBANK, D. W.; ANDERSON, R. S. Tectonic geomorphology. John Wiley \& Sons, 2011. 454 p.

CAMPOS NETO, M. C. et al. Migração de Orógenos e Superposição de Orogêneses: Um Esboço da Colagem Brasiliana no Sul do Cráton do São Francisco, SE - Brasil. Geologia USP - Serie Cientifica, v. 4, n. 1, p. 13-40, 2004.

CHARLTON, R. Fundamentals of fluvial geomorphology. Abingdon: Routledge, 2007. 234 p.

DEHLER N. M.; MACHADO R. Análise geométrica e cinemática das rochas metassedimentares da região de Ijaci, sul de Minas Gerais. Revista Brasileira de Geociências, v. 28, n. 4, p. 413-418, 1998.

HEILBRON, M. et al. Província Mantiqueira. In: MANTESSO-NETO, V.; BARTORELLI, A.; CARNEIRO, C. D. R.; BRITO-NEVES, B. B.; (org) Geologia do Continente Sul-Americano: Evolução da Obra de Fernando Flávio Marques de Almeida, São Paulo: Beca, 2004. p. 203-234. 


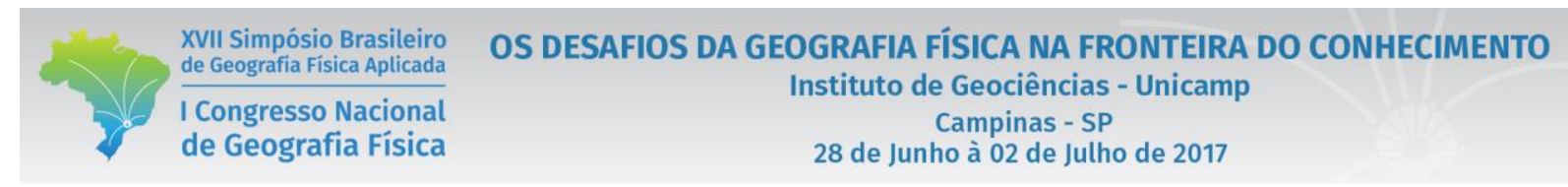

LARUE, J. P. Tectonic influences on the Quaternary drainage evolution on the north-western margin of the French Central Massif: The Creuse valley example. Geomorphology, v. 93, n. 3-4, p. 398-420, 2008.

MORALES, N. et al. Projeto Mapa Neotectônico do Brasil: caracterização da deformação neotectônica do território brasileiro. In: CONGRESSO BRASILEIRO DE GEOLOGIA, 47., 2014, Salvador, Anais, CD-ROM.

OLIVETTI, V. et al. Cenozoic rejuvenation events of Massif Central topography (France): Insights from cosmogenic denudation rates and river profiles. Earth and Planetary Science Letters, v. 444, p. 179-191, 2016.

PINHEIRO, M. R.; QUEIROZ NETO, J. P. Reflexões sobre a gênese da serra geral e da depressão periférica paulista: o exemplo da região da Serra de São Pedro e do baixo Piracicaba, SP. Revista do Instituto Geológico, v. 35, n. 1, p. 47-59, 2014.

PINTO C. P.; SILVA M. A. Mapa Geológico do Estado de Minas Gerais. Codemig/CPRM, 2014.

QUÉMÉNEUR J. J. G. et al. Geologia da Folha Lavras. In: PEDROSA SOARES, A. C.; NOCE, C. M.; TROUW, R. A. J.; HEILBRON, M. (Org.). Geologia e Recursos Minerais do Sudeste Mineiro, Projeto Sul de Minas- Etapa I. Belo Horizonte: COMIG - Companhia Mineradora de Minas Gerais, p. 259-319, 2003.

REZENDE E.A. et al. Fatores controladores da evolução do relevo no flanco NNW do Rifte Continental do Sudeste do Brasil: Uma análise baseada na mensuração dos processos denudacionais de longo-termo. Revista Brasileira de Geomorfologia, v. 14, n. 2, p. 221-234, 2013.

REZENDE, E. A.; CASTRO, P. T. A. Variação espacial e condicionantes do entalhamento fluvial na bacia do Rio Grande, sul de Minas Gerasi. Revista Brasileira de Geomorfologia, v. 17, n. 4, 2016.

RICCOMINI, C. SANT'ANNA, L. G.; FERRARI, A. L. Evolução geológica do Rift Continental do Sudeste do Brasil. In: MANTESSO-NETO, V.; BARTORELLI, A. CARNEIRO, C. D. R.; BRITO-NEVES, B. B. (Ed.). Geologia do continente Sul-Americano: evolução da obra de Fernando Flávio Marques de Almeida. São Paulo: Beca, 2004. p. 383-405.

SAADI, A. Ensaio Sobre a Morfotectônica de Minas Gerais - tensões intra-placa, descontinuidades crustais e morfogênese. 1991. 285 f. Tese (Prof. Titular) - Instituto de Geociências, Universidade Federal de Minas Gerais, Belo Horizonte, 1991.

SAADI, A.; SILVA, L. M.; MAGALHÃES, JR. A. P. Contribuição à discussão das superfícies de aplainamento no sudeste brasileiro, com base na análise quantitativa da paleotopografia do sul de Minas Gerais. Geosul, v. 14, n. 27, p. 569-571, 1998. (Edição especial, Simpósio Nacional de Geomorfologia, 2).

SALGADO A.A.R. et al. Relief evolution of the Continental Rift of Southeast Brazil revealed by in situ-produced ${ }^{10} \mathrm{Be}$ concentrations in river-borne sediments. Journal of South American Earth Sciences, v. 67, p. 89-99, 2016.

SCHUMM, S. A. River variability and complexity. Cambridge University Press, 2007.

TROUW, R. A. J. et al. A new interpretation for the interference zone between the southern Brasília belt and the central Ribeira belt, SE Brazil. Journal of South American Earth Sciences, v. 48, p. 43-57, 2013. 